\title{
FORCA: Um editor de jogo educativo personalizável exportável como objeto de aprendizagem
}

\author{
Luiz A. S. Silva ${ }^{1}$ Eveline J. V. Sá1 ${ }^{1}$ José N. O. Neto ${ }^{1}$, Jeane S. Ferreira ${ }^{1}$ \\ ${ }^{1}$ Instituto Federal de Educação, Ciência e Tecnologia do Maranhão (IFMA) \\ Caixa Postal 65030-005 - São Luís - MA - Brasil. \\ luiz.slz@hotmail.com; eveline,jose.neto,jeane\{@ifma.edu.br $\}$
}

\begin{abstract}
This article presents the development of an editor for the elaboration of a customizable educational game as a learning object molded according to the SCORM pattern. The study follows the context of educational technologies, identifying the theoretical contributions about the use of games in education and learning objects based on SCORM pattern. The Editor FORCA enables the teacher, through its features, to customize the hangman game into any didactic content with the use of different media, aiming to insert the game in the teaching process.
\end{abstract}

Resumo. Este artigo apresenta o desenvolvimento de um Editor para elaboração de jogo educativo personalizável como objeto de aprendizagem modelado segundo o padrão SCORM. O estudo norteia-se no contexto de tecnologias educacionais, identificando as contribuições teóricas sobre a utilização de jogos na educação e objetos de aprendizagem baseados no modelo SCORM. O Editor FORCA possibilita ao professor, através de suas funcionalidades, personalizar o jogo da forca para qualquer conteúdo didático com uso de diferentes mídias, afim de inseri-lo no processo de ensino aprendizagem.

\section{Introdução}

Os jogos educativos são uma importante ferramenta no processo de ensino-aprendizagem. Eles têm o poder de persuadir os aprendizes por apresentarem caráter interativo e por seus atraentes recursos multimídias. Nesse sentido, os jogos digitais têm se inserido no campo da educação como uma ferramenta importante que auxilia a formação de crianças e jovens no processo educativo com sua disseminação cada vez mais rápida e acessibilidade fácil por meio da internet, aparelhos de videogames tradicionais e no próprio celular Prensky (2012).

As tecnologias contemporâneas apresentam uma nova possibilidade de ensinar e aprender, exigindo novas habilidades cognitivas, motoras e de interação com a informação. Muitos professores da atualidade não tiveram em sua formação a orientação e o preparo para lidar com as novas tecnologias que ganham dimensões elevadas a cada atualização de softwares e hardwares. Deste modo, como pensar que os professores sintam-se preparados para lidar com esse contexto tecnológico tão próprio do cotidiano do aluno? 
É nesse contexto que surge a necessidade da criação e utilização de objetos de aprendizagem (OAs). Objetos de aprendizagem ou objetos educacionais são recursos complementares ao processo de aprendizagem que podem ser reutilizados para apoiar a aprendizagem. Dutra e Tarouco (2006) afirmam que o desenvolvimento de conteúdos digitais na forma de objetos de aprendizagem tem sido uma solução crescente na $\mathrm{EaD}$ e destacam que padrões como o SCORM propiciaram maior intercâmbio de objetos de aprendizagem entre ambientes acadêmicos. O padrão SCORM, vai além de um padrão de metadados, pois fornece um nível maior de documentação do que os outros, engloba uma coleção de especificações e normas que definem a inter-relação de objetos de conteúdo, modelos de dados e protocolos ADL (2009). Filho (2009) apresenta uma pesquisa onde se utiliza o padrão SCORM para fazer com que objetos de aprendizagem, que estavam em desuso em função do acoplamento com um ambiente virtual de aprendizagem anterior, voltassem a ser utilizado em um novo ambiente virtual com auxílio de um editor do padrão SCORM.

Objetos de aprendizagem constituem uma ferramenta importante e promissora nesse diálogo de construção de recursos didáticos no contexto das tecnologias digitais, pois permitem que professores-editores dinamizem suas atividades curriculares de modo interativo e não linear. Nesse aspecto que os Jogos Educativos revelam-se como promissores, pois os mesmos possibilitam uma proposta de aprendizagem significativa aliada às práticas pedagógicas contemporâneas de ensino-aprendizagem.

O tipo de jogo escolhido para servir de estudo de caso foi o 'Jogo da Forca', por sua característica genérica (não está atrelado a uma disciplina curricular específica) e pelo seu caráter lúdico. Ao usar o editor FORCA para criar um jogo o professor-editor poderá personalizá-lo tanto em nível de conteúdo educativo quanto em nível visual, ou seja, a apresentação do jogo. Vale ressaltar que o professor-editor não precisará dispor de conhecimentos em qualquer linguagem de programação para personalizar o jogo, o que facilita a interação do mesmo com o editor, amenizando assim as barreiras existentes para lidar com a tecnologia por parte de alguns professores.

Este artigo está organizado da seguinte forma: na seção 2 é apresentada a metodologia utilizada para o desenvolvimento desta pesquisa; na seção 3 , apresenta-se a justificativa e relevância, na seção 4, são apresentados trabalhos relacionados, na seção 5 , é descrito o funcionamento do Editor Forca e do jogo gerado por ele, e por fim as considerações finais na seção 6 .

\section{Metodologia}

A investigação da temática caracterizou-se como um estudo descritivo de abordagem qualitativa que foi desenvolvido com a realização das seguintes etapas:

- Levantamento do referencial teórico e revisão de literatura;

- Verificação de softwares que auxiliem na implementação de objetos de aprendizagem segundo o modelo SCORM;

- Modelagem UML do Editor de Jogo da Forca;

- Codificação e construção do Editor utilizando as linguagens de programação JAVA, HTML, CSS, JavaScript e algumas ferramentas CASE seguindo algumas práticas da metodologia XP. 
VI Congresso Brasileiro de Informática na Educação (CBIE 2017)

Anais do XXVIII Simpósio Brasileiro de Informática na Educação (SBIE 2017)

\section{Justificativa e Relevância}

Jogos Educativos podem ser um importante aliado do processo de aprendizagem, constituindo uma ferramenta de ensino que se diferencia de outras por seu caráter desafiador e lúdico ao possibilitar ao aluno-jogador a aquisição de conhecimentos Pietruchinski et al (2011). Sendo assim, a escolha de um Jogo Educativo deve levar em conta o seu conteúdo, mas sem esquecer a forma como o mesmo se apresenta ao alunojogador, pois "a estrutura do jogo prevê a participação de jogadores com diferentes níveis de habilidade, enfatizando a prática de aprender as dinâmicas do game a partir de tentativas entre erro e acerto" (Gaspar e Garcia, 2011, p.3423).

Fragelli e Mendes (2012) apresentam um jogo educativo na área de física, chamado 'Onde está o Osama', jogo que incentiva os alunos a calcularem somas vetoriais, onde destacam um nível de engajamento dos alunos maior que o de aulas tradicionais, corroborando com as pesquisas que indicam que os jogos podem ser importantes ferramentas no processo de ensino-aprendizagem. Disciplinas que envolvem o desenvolvimento de raciocínio lógico também tem sido contempladas, como observado em Salas e Dantas (2012) que desenvolveram um jogo para ensino de Algoritmos e Programação de Computadores, tornando a aprendizagem de tais conteúdos mais motivadora.

$\mathrm{Na}$ configuração atual do ensino, o professor continua sendo o principal mediador entre os alunos e o conhecimento, portanto Moura e Brandao (2013) ressaltam que 'é fundamental que professor tenha conhecimento sobre as possibilidades do recurso tecnológico para utilizá-lo como instrumento de aprendizagem'. É nesse contexto que surge a necessidade da criação e utilização de objetos de aprendizagem (OAs). Para Dutra e Tarouco (2006) objetos de aprendizagem são recursos complementares ao processo de aprendizagem que podem ser reutilizados para apoiar a aprendizagem.

Mendes, Sousa \& Caregnato (2004) destacam seis características importantes que um objeto de aprendizagem deve possuir: a) Reusabilidade: o objeto de aprendizagem pode ser utilizado diversas vezes e em ambientes de aprendizagem diferentes; $b$ ) Adaptabilidade: o objeto de aprendizagem á adaptável a qualquer ambiente de ensino; c) Granularidade: o objeto de aprendizagem são blocos granulares para facilitar a reusabilidade; d) Acessibilidade: o objeto de aprendizagem deve ser acessível via internet para ser usado em diversos locais; e) Durabilidade: o objeto de aprendizagem deve continuar funcionando independente da mudança de tecnologia; e f) Interoperabilidade: o objeto de aprendizagem deve ser capaz de operar em diversas plataformas de hardware e software.

$\mathrm{Na}$ tentativa de garantir que objetos de aprendizagem sejam criados em consonância com suas características supracitadas, surgem alguns modelos de especificações para criação de OAs que definem desde a modelagem do OA até sua catalogação. Um desses modelos de referência é o SCORM (Sharable Content Object Reference Model) ADL (2014).

Um OA modelado segundo o SCORM é um pacote contendo todos os arquivos que compõe o OA, ou seja, os recursos, e um arquivo manifesto XML que faz o mapeamento desses arquivos, desta forma, os OAs podem ser reutilizáveis, acessíveis, executáveis em ambientes diferentes, e não ficam obsoletos em razão de mudança de tecnologia de ambientes virtuais. Outra vantagem, refere-se ao armazenamento de objetos 
VI Congresso Brasileiro de Informática na Educação (CBIE 2017)

Anais do XXVIII Simpósio Brasileiro de Informática na Educação (SBIE 2017)

de aprendizagem modelados conforme as especificações deste padrão, através de uma estrutura de metadados que acompanham o $\mathrm{OA}$, que facilitam a recuperação e a interoperabilidade dos mesmos.

Assim, a presente pesquisa apresenta a implementação de um Editor para elaboração de jogo educativo personalizável, que poderá servir como material de apoio em aulas presenciais ou à distância.

O 'Jogo da Forca', foi o jogo selecionado para estudo de caso para o desenvolvimento do Editor de jogos parametrizáveis. Ao usar o Editor para criar um jogo o professor-editor poderá personalizá-lo, tanto no que será apresentado em termos de contéudo quanto em nível visual, bem como poderá exportá-lo como objeto de aprendizagem segundo padrão SCORM. Vale ressaltar que o professor-editor não precisará dispor de conhecimentos em qualquer linguagem de programação para personalizar o jogo, o qual constitui um instrumento didático que contribuirá com o processo de ensino-aprendizagem.

\section{Trabalhos Relacionados}

O Hot Potatoes (Bogdanov, 2017) é um software destinado à elaboração de exercícios educativos interativos. O software possui cinco ferramentas para criação de exercícios diferentes: palavras cruzadas, questionário, preenchimento de lacunas, associação entre pares de colunas e um exercício para montar frases embaralhadas. O usuário do Hot Potatoes cria um ou mais exercícios e disponibiliza ao usuário final em forma de uma página HTML. Há diversas pesquisas que reconhecem o Hot Potatoes como uma importante ferramenta que auxilia o processo de ensino-aprendizagem, como é o caso de Aguiar et al (2011) que conclui que o software é válido e adequado como ferramenta que auxilia a construção e aquisição de conhecimento.

Outro software estudado foi o Ardora (Matanza, 2017). Assim como o Hot Potatoes este software permite a criação de atividades educativas personalizadas em forma de página HTML. O Ardora possui mais opções criação de atividades que o Hot Potatoes e possui recurso de gerar conteúdo como pacote SCORM.

Dentre as atividades disponíveis destacam-se as que utilizam imagens, como as atividades de criação de quebra-cabeça, colorir imagem, relacionar uma imagem com o seu nome, etc. Um dos atrativos do Ardora é a facilidade de uso, até mesmo para usuários que não possuem avançados conhecimentos em informática, como destaca Souza et al (2015)

O software Participar 2 (Galvão, Domingues \& Andrade, 2017) tem por objetivo apoiar a alfabetização de jovens e adultos com deficiência intelectual e consiste em uma lista de exercícios voltados para o aprendizado da língua portuguesa. O software apresenta recursos multimídia, como vídeos e imagens, que enriquecem a interação com o usuário. Diferente do Hot Potatoes, o Participar 2 não é um software para elaboração de exercícios, nele os exercícios já estão prontos e são exibidos ao usuário progressivamente.

As atividades do software Participar 2 são compostas de jogos de palavras, que se assemelham ao jogo da forca, por esta razão este software também fora analisado na elaboração desta pesquisa. 
VI Congresso Brasileiro de Informática na Educação (CBIE 2017)

Anais do XXVIII Simpósio Brasileiro de Informática na Educação (SBIE 2017)

\section{Editor do Jogo da Forca}

A implementação do Editor se deu com utilização da tecnologia JAVA. O jogo gerado pelo Editor é constituído por uma página web com tecnologia HTML, CSS e JavaScript, o que garante que ele irá funcionar na maioria dos browsers (navegadores) atuais, uma vez que estas tecnologias são amplamente utilizadas. Este Editor permite que o jogo criado possa ser encapsulado sob a forma de objeto de aprendizagem segundo o modelo SCORM (Sharable Content Object Reference Model) (ADL, 2014). Com isso pretendese garantir que ele possua as características de reusabilidade, acessibilidade, interoperabilidade e durabilidade, entre outras.

Para construir o Jogo da Forca que será distribuído aos alunos em uma página HTML, o professor-editor dispõe do software Editor, cuja interface gráfica de usuário principal é ilustrada na Figura 1. Esta interface possui em sua parte superior botões de comando para a adição de fase, adição de palavras nas fases, criação do jogo simples (sem SCORM) e criação de objeto de aprendizagem (com SCORM), cada botão possui um ícone associado, para que a interface gráfica do usuário fique mais intuitiva. A seguir serão descritos cada uma dessas funcionalidades:

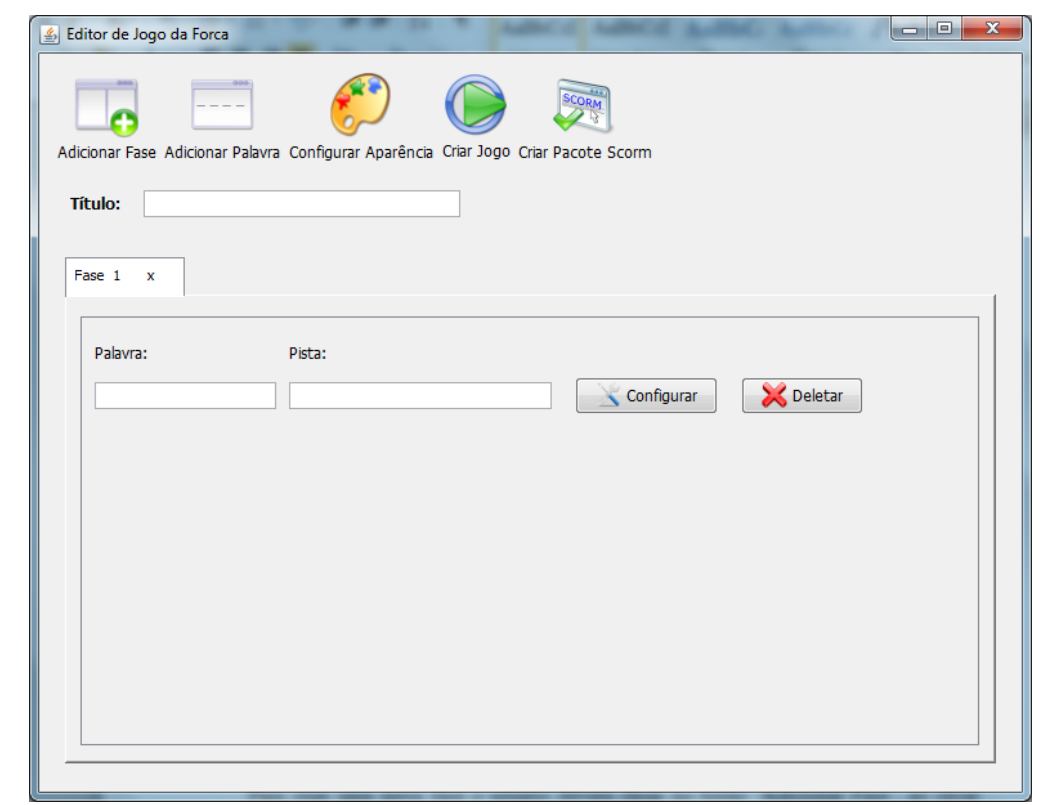

Figura 1. Interface gráfica do usuário principal do editor.

- Adicionar fase: Cada fase é montada em uma guia ou aba, diferente na interface do usuário. Para criar uma nova fase o professor-editor deverá clicar no botão 'Adicionar Fase', ao clicar nesse botão uma nova guia é criada, já contendo a estrutura para receber a primeira palavra desta fase.

- Adicionar Palavra: Para aumentar o número de palavras por fase o professor-editor deve clicar no botão 'Adicionar Palavra', e uma nova estrutura para palavra é exibida na aba da fase atual, onde são inseridos: a palavra, a dica referente a esta palavra, e a "configuração da palavra", onde o professor poderá adicionar um arquivo multimídia que será exibido junto à palavra. Este arquivo pode ser uma imagem, um vídeo ou um 
áudio. Define-se também a quantidade de erro permitida a cada palavra (por padrão essa quantidade é de cinco erros, mas esse valor pode variar entre um e vinte e seis quantidade de letras do alfabeto português). O usuário poderá também adicionar uma mensagem que aparecerá quando o jogador acertar ou errar a palavra.

- Configurar aparência: $\mathrm{Na}$ janela de configuração de aparência o usuário escolhe as cores que serão exibidas na tela do jogo. Há 10 elementos da página HTML que podem ter a sua cor alterada, como: o plano de fundo da página, o título do jogo, cor do teclado, cor das letras da palavra, etc.

- Criar jogo: Após configurar o jogo, o usuário deverá clicar na opção de criar jogo para criar toda a estrutura necessária para o funcionamento do jogo. É gerada uma árvore de diretórios, cuja raiz possui a página HTML principal do jogo, os elementos multimídias e de configuração da página como arquivo CSS e JavaScript ficam em subdiretórios. A partir deste ponto o jogo está pronto para a distribuição, podendo ser hospedado em servidor ou distribuído para os jogadores de maneira off-line.

- Criar Pacote SCORM: Se preferir, o usuário poderá criar o jogo como objeto de aprendizagem modelado segundo o SCORM. Nesta opção os diretórios e subdiretórios criados são idênticos aos criados no processo anterior, com a diferença que a pasta principal é empacotada pelo modo de compressão ZIP, e há a inclusão dos metadados necessários para o modelo SCORM.

\subsection{O Jogo da Forca}

O Jogo da Forca gerado pelo editor consiste em um desafio de adivinhação de palavras. O jogo pode ser constituído de mais de uma palavra e as palavras podem estar agrupadas em fases. O jogador tentará acertar uma palavra por vez, escolhendo a cada ciclo de jogada uma letra que ele supõe fazer parte da palavra. Após acertar todas as letras que compõem a palavra o usuário é informado que acertou, então o ciclo dessa palavra é encerrado e se inicia o ciclo da próxima palavra.

No início de cada ciclo de uma palavra são exibidas lacunas na tela que representam cada letra que a palavra possui. O número de lacunas corresponde exatamente ao número de letras da palavra. Abaixo dessas lacunas há um teclado virtual para que, com o mouse ou tocando em tela (telas touch screen), o jogador possa escolher as letras que irá jogar, devendo escolher sempre uma letra por vez. Sempre que o jogador acerta uma letra lhe é informado que o seu número de acertos aumentou, nesse caso a letra escolhida é exibida preenchendo a lacuna correspondente à sua posição na palavra. Se o número de acertos do jogador for igual ao número de letras da palavra, o jogador é informado que completou a palavra, passando para a próxima encerrando o ciclo desta palavra. Quando o jogador escolhe uma letra que não faz parte da palavra o seu número de erros aumenta e caso o número de erros seja maior que a quantidade máxima de erros permitida, que é definida pelo professor-editor, o jogador é informado que errou a palavra e o ciclo da palavra atual recomeça. Cada vez que o usuário pressiona uma letra no teclado virtual, esta desaparece do teclado; independente de ser uma letra certa ou não, para que o usuário não torne a utilizá-la.

O jogo é exibido em uma página HTML, a apresentação da página depende do contexto da tela do usuário, pois ela é responsiva. Há duas formas de visualização do conteúdo, na primeira os componentes são dispostos horizontalmente, como pode ser observado na Figura 2. Nesta configuração os elementos visuais que constituem o jogo são um texto centralizado na parte superior da tela com o título do jogo, no lado esquerdo 
VI Congresso Brasileiro de Informática na Educação (CBIE 2017)

Anais do XXVIII Simpósio Brasileiro de Informática na Educação (SBIE 2017)

da tela há uma imagem que representa a evolução do jogador no decorrer do jogo: uma imagem simbolizando um rosto com um sorriso feliz quando o ciclo da palavra é iniciado, uma imagem simbolizando um rosto com um sorriso alegre quando os erros do jogador para aquele ciclo de palavra estão em torno de $50 \%$ do total de erros permitido para aquela palavra; uma imagem simbolizando um rosto com uma expressão séria quando os erros do jogador estão próximos de $75 \%$ do total de erros permitidos e uma imagem simbolizando um rosto com expressão preocupada quando o limite máximo de erros é ultrapassado.

No centro da tela são exibidas as lacunas referentes às letras das palavras e o teclado virtual. Sempre que o usuário escolhe uma letra ela desaparece do teclado para que não possa ser escolhida novamente, e é exibida no lado esquerdo da tela como letra escolhida. Sempre que a letra escolhida está contida na palavra ela substitui a lacuna na posição em que a letra está na palavra.

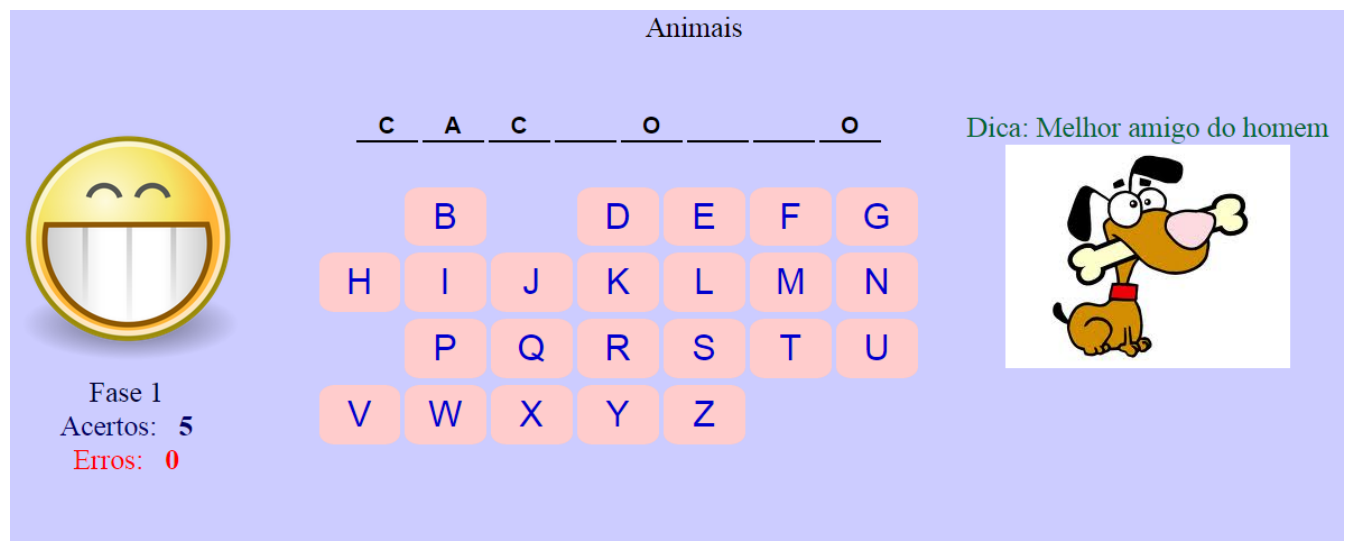

Figura 2. Exemplo de jogo da forca, disposto horizontalmente na tela.

No lado direito da tela são exibidas as dicas das palavras. As dicas são pistas formadas por palavras ou frases que ajudam os jogadores a adivinhar a palavra. Cada palavra pode ter uma dica em forma de texto, além disso, as palavras podem ter uma dica multimídia associada. Essa dica pode ser um arquivo de imagem (no formato PNG, JPEG e GIF), arquivo de áudio (MP3, OGG) e vídeo (MP4).

Esta disposição é exibida em desktops, tablets ou celulares em posição landscape (horizontal). Em tablets e celulares na posição portrait (vertical).

Quando o usuário acerta a palavra, uma mensagem é exibida em uma janela do tipo modal, informando a palavra que estava sendo jogada. Caso o professor-editor que editou o jogo tenha digitado uma mensagem de acerto para essa palavra aparecerá no mesmo modal, abaixo da palavra que estava em jogo, como na Figura 3, caso contrário a mensagem será 'Parabéns, você acertou'. 
VI Congresso Brasileiro de Informática na Educação (CBIE 2017)

Anais do XXVIII Simpósio Brasileiro de Informática na Educação (SBIE 2017)

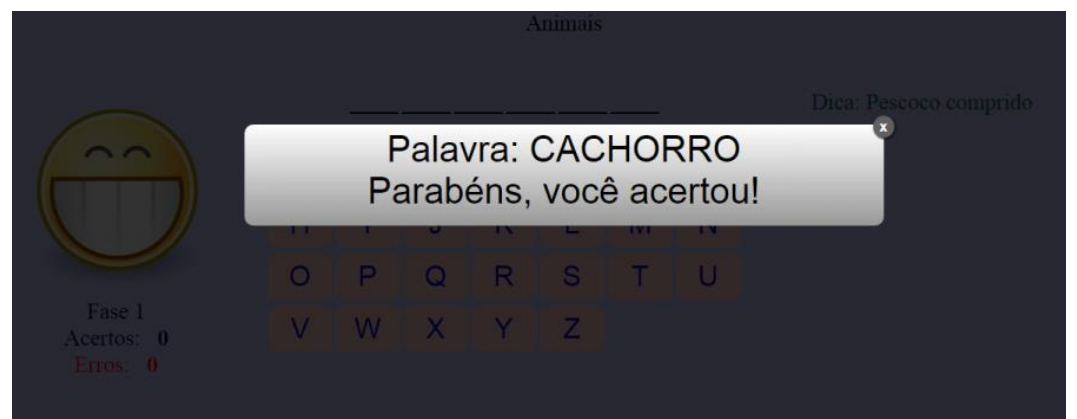

Figura 3. Mensagem de acerto ao término de uma palavra.

Caso o aluno-jogador esgote as chances para acertar uma palavra, uma mensagem, também em uma janela modal, aparecerá ao usuário informando que ele errou a palavra. Se o professor-editor tiver digitado uma mensagem de erro, a mensagem informando o erro será a digitada por ele, caso contrário a mensagem exibida será a mensagem do sistema: 'Você errou a palavra, tente novamente.'. Sempre que o aluno-jogador completa uma palavra, o jogo muda automaticamente para a próxima; se houver. Se a palavra é a última da fase atual, uma mensagem informa que ele passou de fase, se a palavra for a última da última fase um alerta sinaliza o fim do jogo.

Cabe ressaltar que todo conteúdo do jogo é de responsabilidade do professoreditor, portanto, o nível de dificuldade do jogo e suas respectivas fases ficam a cargo do professor-editor, que irá estabelecer esse nível a partir dos conteúdos que abordar.

\section{Considerações finais}

A aprendizagem baseada em jogos promove um diálogo propositivo entre professor e alunos, promovendo uma maior motivação por parte dos alunos e interesse pelos conteúdos abordados em sala de aula, possibilitando um aprendizado efetivo. "A intermediação professor-computador-aluno passa necessariamente pelo software que deve ser a ferramenta usada na mediação do conhecimento" (Teixeira e Araújo, 2007, p. $5)$.

A partir destas reflexões, a primeira etapa metodológica foi o levantamento de algumas problematizações que nortearam o cenário de aprendizagem traçado (a definição de um jogo de caráter simples e próprio do senso comum e imaginário de crianças em sala de aula: o jogo da forca) bem como o desenho do jogo (formato, layout, apresentação do conteúdo), subsidiando a construção do editor. Portanto, "para o desenvolvimento de jogos educacionais é preciso pensar um tema a ser proposto, quais os objetivos a serem alcançados e de que forma vamos organizar este material" (Tarouco et al, 2004, p. 4).

Nessa perspectiva, para o desenvolvimento do editor do Jogo de Forca buscou-se um layout de fácil acesso e intuitivo para personalização pelo professor-editor conforme os objetivos instrucionais e necessidades do contexto de aprendizagem do aluno, promovendo uma aproximação deste com a ferramenta tecnológica. Pensou-se também na escolha do Jogo da Forca por ser próprio do senso comum de crianças e adolescentes, gerando no imaginário do aluno-jogador a curiosidade da possível descoberta de uma palavra (que no caso estará associada ao contexto educativo proposto: conteúdo, área de conhecimento, disciplina, etc.) antes que o jogo finalize. Como trabalhos futuros, pretende-se estender o editor para outros tipos de jogos, por exemplo, Palavras-Cruzadas, Memória, Flascards, etc., para então, construir uma arquitetura de um editor genérico que 
VI Congresso Brasileiro de Informática na Educação (CBIE 2017)

Anais do XXVIII Simpósio Brasileiro de Informática na Educação (SBIE 2017)

suporte a escolha do tipo do jogo pelo professor, e em seguida, este possa configurar os parâmetros do jogo de acordo com o planejamento de sua aula.

Portanto, todo o processo que levou a elaboração deste estudo evidenciou a necessidade de maior aprofundamento sobre a elaboração de Editor de Jogos Educativos, a partir da caracterização de cenários de aprendizagem diversos e a aplicação da pesquisa e estudo de caso junto a professores-editores e alunos-jogadores em escolas e/ou na educação não formal, mantendo uma postura aberta para a descoberta de diferentes olhares, interpretações e práticas educativas relacionadas às tecnologias contemporâneas. A elaboração e discussão sobre jogos computadorizados e educacionais no contexto das TIC's não se conclui, mas instiga caminhos, olhares e diálogos em processo.

\section{Referências}

ADL - ADVANCED DISTRIBUTED LEARNING. Disponível em: <http://www.adlnet.gov>. Acesso em julho/2017

AGUIAR, Daiane Ignácio de; ZANELLA, Renata; OLIVEIRA, Tiago Santos. Apresentação do Software de Autoria Hot Potatoes como Ferramenta de Apoio no Ensino /Aprendizado em Turmas de EJA. Revista iTEC, Vol. II, No 2, Jul. 2011. Disponível em <http://www.facos.edu.br/old/galeria/130072011050718.pdf>. Acesso em: julho/2017

BOGDANOV, Stan. Hot Potatoes Home Page. Disponivel em https://hotpot.uvic.ca/ acesso em julho/2017.

DUTRA, Renato Luís de Souza; TAROUCO, Liane Margarida Rockenbach. Objetos de Aprendizagem: Uma comparação entre SCORM e IMS Learning Design. RENOTE. Novas Tecnologias na Educação, CINTED-UFRGS. 2006.

FILHO, Luiz Carlos Barreto Da Silva. Modelagem de Objetos de Aprendizagem Utilizando o Modelo SCORM. 2009. 43 f. Monografia. (Ciência da Computação). Universidade Federal da Bahia. 2009.

FRAGELLI, Ricardo Ramos; MENDES, Fábio Macedo. “Onde Está o Osama?”: Um Jogo Educativo na Área de Física. 2012. Disponível em: <http://repositorio.unb.br/handle/10482/12097>. Acesso em: outubro/2014.

GALVÃO, Tiago M. F., DOMINGUES, Renato Silva e ANDRADE, João Paulo de Conti. Participar 2. Disponivel em http://www.projetoparticipar.unb.br/participar2 acesso em julho/2017.

GASPAR, Débora da Rocha e GARCIA, Fernando Herraiz. Quando o jogo eletrônico vira arte: algumas considerações sobre o "Game Art". In: Encontro Nacional Associação Nacional de Pesquisadores em Artes Plásticas, 20, 2011. Disponível em <http://www.anpap.org.br/anais/2011/pdf/cpa/debora_rocha_gaspar.pdf >. Acesso em novembro/2014.

MATANZA, José Manuel Bouzán. Ardora Home Page. Disponível em: <http://webardora.net/>. Acesso em: julho/2017

MENDES, Rozi Mara; SOUZA, Vanessa Inácio; CAREGNATO, Sônia Elisa. A propriedade intelectual na elaboração de objetos de aprendizagem. 2004. Disponível em 
VI Congresso Brasileiro de Informática na Educação (CBIE 2017)

Anais do XXVIII Simpósio Brasileiro de Informática na Educação (SBIE 2017)

<http://www.lume.ufrgs.br/bitstream/handle/10183/548/000502901.pdf?sequence=1 \&locale $=$ pt_BR $>$. Acesso em julho/2017.

MOURA, Eliane \& BRANDÃO, Edemilson. O uso das tecnologias digitais na modificação da prática educativa escolar. 2013. Disponível em <http://www.faers.com.br/uploads/revista_fazer/f397e7592079dd8b62fba98e2b964f 5f.pdf $>$. Acesso em julho/2017.

PIETRUCHINSKI, Coelho Neto J.; MALUCELLI, A.; REINEHER, S. (2011) “Os jogos educativos no contexto do SBIE: uma revisão sistemática de Literatura". In: XXII Simpósio Brasileiro de Informática na Educação - SBIE, p.476-485.

PRENSKY, M. Aprendizagem Baseada em Jogos Digitais. São Paulo: Editora Senac, São Paulo, 2012.

RODOLPHO, Everaldo Rodrigo. Convergência digital de objetos de aprendizagem SCORM. 2009. 124 f. Dissertação (Mestrado em Ciência da Computação). UNESP, 2009.

SANCHIS, Isabelle de Paiva e MAHFOUD, Miguel. Construtivismo: desdobramentos teóricos e no campo da educação. Revista Eletrônica de Educação, v. 4, n. 1, mai. $2010 . \quad$ Artigos. Disponível em <http://www.reveduc.ufscar.br/index.php/reveduc/article/viewFile/120/86>. Acesso em julho/2017.

SALES, Chrystian Gesteira; DANTAS, Vanessa Farias. ProGame: um jogo para o Ensino de algoritmos e programação. 2010. Anais do XXI SBIE Simpósio Brasileiro de Informática Na Educação. João Pessoa - PB.

SOUZA, Adriana Sadowski de; PARREIRA, Fábio José; FALKEMBACH, Gilse Morgenthal; SOUZA, Naidú Gasparetto de; SILVEIRA, Sidnei Renato. Alternativas para Construção de Objetos de Alternativas para Construção de Objetos de Aprendizagem: um estudo de caso voltado à definição de uma arquitetura para adaptação de cursos na modalidade de Educação a Distânciaum estudo de caso voltado à definição de uma arquitetura para adaptação de cursos na modalidade de Educação a Distância. Revista de Ciência e Tecnologia, V.1, n.1. 2015. Disponívem em <https://revista.ufrr.br/rct/article/view/2498> Acesso em: julho/2017.

TAROUCO, Liane Margarida Rockenbach; ROLAND, Letícia Coelho; FABRE, MarieChristine Julie Mascarenhas; KONRATH, Mary Lúcia Pedroso. Jogos Educacionais. 2004. Disponível em: <http://www.cinted.ufrgs.br/ciclo3/af/30jogoseducacionais.pdf $>$. Acesso em julho/2017.

TEIXEIRA, Núbia Poliane Cardoso e ARAÚJO, Alberto Einstein Pereira de. Informática e Educação: uma reflexão sobre novas metodologias. 2007. Disponível em <http://www.hipertextus.net/volume1/artigo13-nubia-alberto.pdf >. Acesso em julho/2017. 